\title{
Using a Hybrid Evolutionary Algorithm for Solving Signal Transmission Station Location and Allocation Problem with Different Regional Communication Quality Restriction
}

\author{
Ta-Cheng Chen ${ }^{1,2, *}$, Sheng-Chuan Wang ${ }^{3}$, Wen-Cheng Tseng ${ }^{2}$ \\ ${ }^{1}$ Department of M-Commerce and Multimedia Applications, Asia University, Taichung, Taiwan \\ ${ }^{2}$ Department of Information Management, National Formosa University, Yunlin, Taiwan \\ ${ }^{3}$ Department of Finance, Asia University, Taichung, Taiwan \\ Received 05 December 2019; received in revised form 06 March 2020; accepted 19 May 2020 \\ DOI: https://doi.org/10.46604/ijeti.2020.5054
}

\begin{abstract}
This study aims to investigate the signal transmission station location-allocation problems with the various restricted regional constraints. In each constraint, the types of signal transmission stations and the corresponding numbers and locations are to be decided at the same time. Inappropriate set up of stations is not only causing the unnecessary cost but also making the poor service quality. In this study, we proposed a hybrid evolutionary approach integrating the immune algorithm with particle swarm optimization (IAPSO) to solve this problem where each of the regions is with different maximum failure rate restrictions. We compared the performance of the proposed method with commercial optimization software LINGO®. According to the experimental results, solutions obtained by our IAPSO are better than or as well as the best solutions obtained by LINGO®. It is expected that our research can provide the telecommunication enterprise the optimal/near-optimal strategies for the setup of signal transmission stations.
\end{abstract}

Keywords: location-allocation problem, hybrid evolutionary approach, immune algorithm, particle swarm optimization

\section{Introduction}

The combinatorial optimization problem is considered to be quite important because it can be applied to the establishment of mathematical models for various domain problems. However, this type of problem has difficulty in finding the optimal solution, especially for a large scale of combinatorial optimization problems. Therefore, various mathematical programming, heuristic algorithms, evolutionary algorithms, and their blending methods have been developed in the past to solve such problems. The practical examples of the combinatorial optimization problem that can be applied, such as the location and allocation problems [1-3] of communication signal stations.

The "Fifth Generation (5G) Mobile Communication System" has been launched and rapidly adopted in the industry. As a result, the population using wireless communication technology is increasing dramatically. The use of 5G technology is revolutionizing the way people live. However, the disadvantage of $5 \mathrm{G}$ is that the longer the distance, the weaker the diffraction ability of the signal, and the coverage distance of the signal station is reduced either [4]. It implies that when better communication quality is required, the telecommunications company must deploy more $5 \mathrm{G}$ signal stations and consider how to

* Corresponding author. E-mail address: tchen@nfu.edu.tw 
configure them. The communication industry has all thought about how to deploy base stations with limited resources to improve the reliability of communication quality and enable customers to obtain excellent communication services. Therefore, the solution to these problems must rely on the proper deployment of the mobile communication base stations.

The relative research is rarely investigated in the literature. The pioneers studying the problems were Drezner and Wesolowsky [5]. They proposed their approaches to find the optimal locations for a number of detectors while the corresponding number and types of the detectors were given. The multiple detector problems in their study appear to $p$-center problems [6] while one detector location problem looks like a 1-center or minimax single facility location problem [7]. Chen $e t$ al. [8] extended their study into nonlinearly constrained various signal detector location-allocation problems; the categories of detectors and the corresponding amount and positions were decided simultaneously. In the problem model, the detection signal strength of the detector declines as the detection distance increases. So, the above problems are the difficulties to be solved in the study. However, it is noted that the maximum detecting failure rate to be minimized is in a specified "identical" zone in these references. Nevertheless, the issue of multiple zones with various requirements of communication quality hasn't been discussed yet.

Recently, many evolutional computation approaches have been employed to solve lots of optimization problems. Above all, the immune algorithm (IA) [9-12] and particle swarm optimization (PSO) [13-16] are widely used in literature for many successful applications. The merit of such heuristic methods mentioned above is that it is little or no needed assumption. Above all, they can seek vast heterogeneous candidate solution spaces. However, these heuristic methods cannot ensure to provide the optimal solution(s). In this study, we proposed a hybrid evolutionary computation approach that mixes IA and PSO instead of using the two-phase approach of using IA and PSO $[8,17]$. The design of the proposed approach uses IA to decide the number of the signal transmission stations and the category of each station simultaneously, and then uses PSO to find the optimal locations for all the stations provided by IA. The advantage of using AI is its excellent global solution searching ability. However, its disadvantage is that it takes more computational time because of the complex computation procedures. On the contrary, the merits of applying PSO is that its operation convergence speed is fast but not suitable for global solution searching. Therefore, we integrated the advantages of the IA and PSO to solve the signal base station deployment problem.

The arrangement of this paper is as follows. In Section 2, we define the notations, assumptions, and the mathematical model of this signal transmission station location and allocation problem with different regional communication quality restrictions. In Section 3, we present the grid computing based on the computational procedure of the hybrid evolutionary algorithm for solving the signal transmission station location and allocation problems. Experimental results of the proposed hybrid evolutionary approach are presented and discussed in Section 4 to examine the manifestation of the proposed method. In this section, the solutions found by using our approach were compared with those found by using Lingo ${ }^{\circledR}$. The Summary of this research is concluded in Section 5 .

\section{Problem Model and Assumptions}

For the proposed problem, the nomenclature was used as follows:

\begin{tabular}{|c|l|}
\hline $\mathrm{m}$ & the number of the signal transmission station category. \\
\hline $\mathrm{x}_{\mathrm{i}}$ & the number of the signal transmission station category $i, 1 \leq i \leq m$. \\
\hline $\mathrm{s}_{\mathrm{i}}$ & the signal decay exponent of signal transmission station type $i$. \\
\hline $\mathrm{a}_{\mathrm{i}}$ & the setup cost of the signal transmission station category $i$. \\
\hline $\mathrm{d}$ & the distance between a specified signal transmission station and a service point. \\
\hline$\pi(\mathrm{d})$ & a distance related the monotonically signal decay function. \\
\hline $\mathrm{X}_{\mathrm{ij}}$ & the location of the $j^{\text {th }}$ signal transmission station of category $i . \mathrm{i}=1,2, \ldots, \mathrm{m} ; \mathrm{j}=1,2, \ldots, \mathrm{x}_{\mathrm{i}} ;$ for all $\mathrm{i}$. \\
\hline $\mathrm{d}\left(\mathrm{X}_{\mathrm{k}}, \mathrm{X}_{\mathrm{ij}}\right)$ & $\begin{array}{l}\text { the distance between the } j^{\text {th }} \text { signal transmission station of category } i \text { and a service point in the } k^{\text {th }} \text { area. } \\
\mathrm{j}=1,2, \ldots, \mathrm{x}_{\mathrm{i}} ; \text { for all } \mathrm{i} ; 1 \leq \mathrm{k} \leq \mathrm{K} .\end{array}$ \\
\hline $\mathrm{f}_{\mathrm{k}}$ & the maximum failure rate which is not serviced in the $k^{\text {th }}$ area. \\
\hline
\end{tabular}


For the proposed signal transmission station location-allocation problem with multiple regional communication quality restriction problems, three types of decision variables are decided. Moreover, one of the assumptions is that various zones are with the corresponding maximum failure rate restrictions. The decision variables include the numbers of signal transmission stations, the corresponding categories and their locations. The model of the multiple category detector location-allocation problems with a linear resource limitation constraint is considered in this study, and the formulation is modeled as a mixed-integer nonlinear programming problem. In this research, the signal transmission station deployment problem is with "different" regional communication quality restrictions when the problem investigated by Chen et al. [8] is only with the "single" regional communication quality restriction. In other words, we extend the problem discussed by Chen et al. [8] to be the multiple regions with the corresponding communication quality requirement.

The signal decay function can be formulated by a distance related to the probability function. For most realistic applications, the function can be considered as a monotonically decreasing function to the distance. By getting the distance $d$ and signal decay exponent $s$ of detector type $i$, the signal decay function $[5,8]$ can be described as:

$$
\pi(\mathrm{d})=\mathrm{e}^{-\mathrm{s}_{\mathrm{i}} \mathrm{d}}
$$

Assume the probability that a communication event occurring at location $X_{k}$ which is not served by all the signal transmission stations is formulated $[5,8]$ as:

$$
\prod_{i=1}^{m} \prod_{j=1}^{x_{i}}\left(1-\pi\left(d\left(X_{k}, X_{i j}\right)\right)\right)
$$

The probability can be looked as the communication service failure rate at a location point within the $k^{\text {th }}$ service zone. In other words, the maximum communication failure rate occurring in the $k^{\text {th }}$ area should not be higher than the communication quality requirement limit of the area. While the above failure rate of a location point is defined, the problem therefore can be formulated as:

$$
\max _{\mathrm{X}_{\mathrm{k}}}\left\{\prod_{\mathrm{i}=1}^{\mathrm{m}} \prod_{\mathrm{j}=1}^{\mathrm{x}_{\mathrm{i}}}\left(1-\pi\left(\mathrm{d}\left(\mathrm{X}_{\mathrm{k}}, \mathrm{X}_{\mathrm{ij}}\right)\right)\right)\right\} \leq \mathrm{f}_{\mathrm{k}}
$$

which can be briefly expressed as:

$$
\max _{\mathrm{X}_{\mathrm{k}}}\left\{\prod_{\mathrm{i}=1}^{\mathrm{m}}\left(1-\mathrm{e}^{-\mathrm{s}_{\mathrm{i}} \mathrm{d}}\right)\right\} \leq \mathrm{f}_{\mathrm{k}}
$$

for all $i \& j$. Then, the overall signal transmission stations are allocated in various regions with the constraints of the required communication quality and the total cost should be minimized. So, the objective can be expressed as:

$$
\min \sum_{i=1}^{m} x_{i} a_{i}
$$

\section{The Proposed Hybrid Evolutionary Algorithm}

In our study, the proposed approach adopted the combination of IA and PSO to solve the nonlinearly constrained problems which has been illustrate in previous session, and we named the proposed method as IAPSO. In the issues, different regions have different communication quality restrictions. The types of signal communication stations, the corresponding 
numbers, and locations are to be determined simultaneously to minimize total costs of setting up. In the proposed approach, the number of signal communication stations with the corresponding categories is decided by the immune algorithm firstly. Then, the best locations of each station are provided by using particle swarm optimization. Besides, since our proposed hybrid evolutionary algorithm is computationally time-consuming, this is also a problem that must be overcome.

\subsection{The computational procedures of IAPSO}

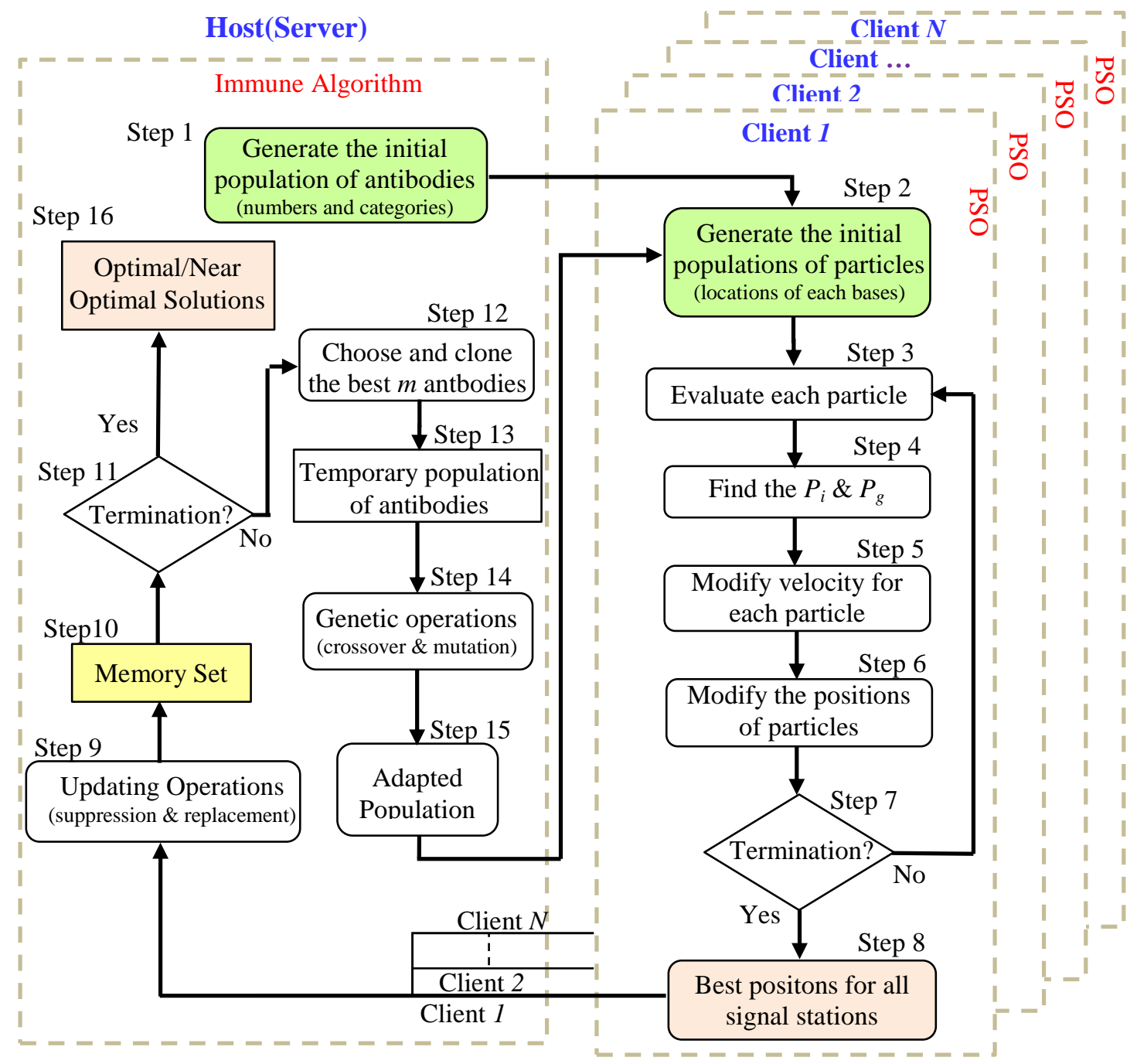

Fig. 1 The proposed hybrid evolutionary computation method-IAPSO

Because the complex evolutionary computation procedures of the proposed approach resulted in expensive computational cost, we utilized the grid computing technology in this study for solving the above difficulty. The computation architecture is including a single host computer with multiple client computers. The host computer is responsible for executing the computation of IA for deciding the number of signal stations and the type of each station; the numerous client computers are to carry out the computation of PSO to find the best locations for each station in different regions. We used the Matlab ${ }^{\circledR}$ code to

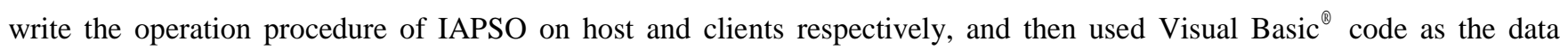
transmission interface architecture of host and clients. The procedure of the proposed grid computing is presented in Fig. 1, and the discussion comes in sequence:

Host computational procedure (single computer)

In this procedure, various combination of the of signal detector numbers and the corresponding categories are generated by immune algorithm. 
A. Start and execute Step 1 through VB calling the COM file which is generated by Matlab ${ }^{\circledR}$.

Step 1. Generate an initial population of antibodies in the form of binary streams randomly. Pass the output values (representing the number and category of all signal transmission stations) through the VB program stored as variables and then pass these variables to the client computers.

Client computational procedure (multiple computers)

B. Call the COM file and perform the PSO algorithm from Step 2. to Step 8.

Step 2. Generate an initial population of particles by varying the positions of a solution randomly.

Step 3. Evaluate every particle (solution) based on the Eq. (5).

Step 4. Update the values of $p_{i}$ (best location this particle has experienced) and $p_{g}$ (the best position of the colony) respectively. where $p_{i}=\left(p_{i 1}, p_{i 2}, \ldots, p_{i N}\right)$, and $p_{g}\left(p_{g 1}, p_{g 2}, \ldots, p_{g N}\right)$.

Step 5. Adjust the velocity of each particle according to $p_{i}$ and $p_{g}$ from Step 4 by using [18]:

$$
v_{\text {in }}(k+1)=w v_{\text {in }}(k) \cdot \Delta t+c_{1} \operatorname{rand}_{1 n}() \cdot\left(p_{\text {in }}-x_{i n}(k)\right) / \Delta t+c_{2} \operatorname{rand}_{2 n}() \cdot\left(p_{g n}-x_{i n}(k)\right) / \Delta t
$$

where $w$ is an inertial weight $(0 \leq w \leq 1)$ that determines how much of the particle's previous velocity to be maintained; $\mathrm{c}_{l} \& \mathrm{c}_{2}$ are the positive acceleration; $\operatorname{rand}_{l n}() \& \operatorname{rand}_{2 n}()$ mean samplings of the uniform random sequences received from $\mathrm{U}(0,1) ; \Delta t$ is the step value of timing.

Step 6. Modify each particle's position based on its updated velocity by using Eq. (7) so that the position of each particle can be then updated.

The particles fly through the solution space by adjusting the location of the $i^{\text {th }}$ particle at time $t$ as [13]:

$$
x_{i}(k+1)=x_{i}(k)+v_{i}(k) \cdot \Delta t
$$

where $k$ is the iteration number; the current location and velocity are described by $x_{i}=\left(x_{i 1}, x_{i 2}, \ldots, x_{i N}\right)$ and $v_{i}=\left(v_{i 1}, v_{i 2}, \ldots, v_{i N}\right)$ in which $N$ means the number of independent variables to be found.

Step 7. Check the termination criterion, if not terminate then go to Step 3. Otherwise go to Step 8.

Step 8. Stop the solution improvement procedure. The best solution, i.e., the best locations for all signal transmission stations are found based on the given number and category of transmission stations. Go the next step and send the solution to the host computer and activate the host computational procedure.

Host computational procedure (single computer)

Step 9. Update the antibodies in the memory set by using suppression and replacement operations. In the suppression operations, the antibodies will be eliminated while their structures are too similar so that the individuals in the memory set can keep the diversity. In the replacement operations, the new affinity values of these new individuals (antibodies) from Step 8 are calculated. The new individuals who are superior to the individuals in the memory-set are chosen to exchange the inferior ones.

Step 10. The newly updated memory set is provided.

Step 11. Check the termination criterion, if not terminated, then go to Step 12. Otherwise go to Step 16. 
Step 12. Select the best $m$ antibodies with the highest affinity values and then clone these $m$ antibodies.

Step 13. The temporary population of antibodies is generated.

Step 14. The temporary population in Step 13 has gone through the crossover and mutation processes [19]. Therefore, a new adaptive antibody population has been yielded.

Step 15. After the adapted population of antibodies is produced, go to Step 2.

Step 16. End. The optimal or near optimal solutions are found.

\subsection{The solution representation}

The solution representations for IA and PSO are designed as the binary streams, and they are described as follows. In this study, the IA's solution representation is encoded by strings of binary digits, as shown in Fig. 2 [8]. A string is separated into two substrings and then decoded into several values sequentially. The first binary substring standing for the number of signal communication stations is decoded into an integer $(g)$. It is noted that a binary string can be translated into a real number and then rounded up to be an integer. While the amount of stations is decided, the second binary substring is divided into $g$ substrings. For each of g substrings, it contains two sections, including the detector category and the approximated location, respectively. Thus, the proposed binary string can represent the general form of the solutions. In our approach, the number of signal communication stations and the corresponding category determined by IA firstly and then PSO find the best positions for each station. Finally, the setup cost for each solution can be obtained. So, the solution representation of PSO is formed as a string which can be translated into real numbers, as shown in Fig. 3 [8]. Each string is divided into $g$ substrings (locations), and each substring represents a coordinate $(x, y)$ of the corresponding signal communication station.

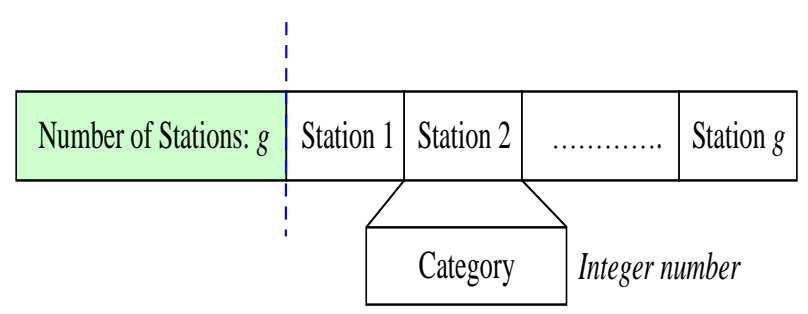

Fig. 2 Solution representation of IA

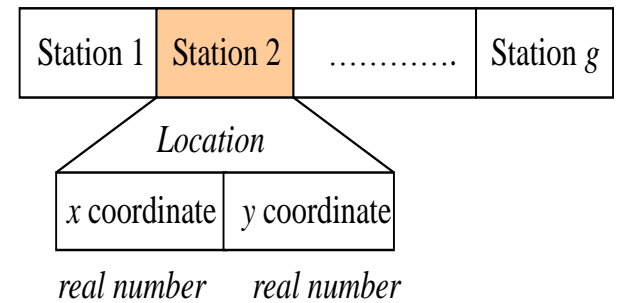

Fig. 3 Solution representation of PSO

\subsection{Constrained optimization}

For propagating a better new particle for the next generations (iterations), the evaluation of each particle is a necessary process for PSO. For overcoming the difficulty of these constraint violations, a penalty function has to be defined. A penalty will be incurred and generated by a penalty function when a solution violates any constraint. The amount of punishment for an infeasible solution is decided by how far away from the feasible region. According to the Eq. (3) in Section 2 , for individual $k$, the penalty function of the constraint violation for the $k^{\text {th }}$ individual can be expressed as:

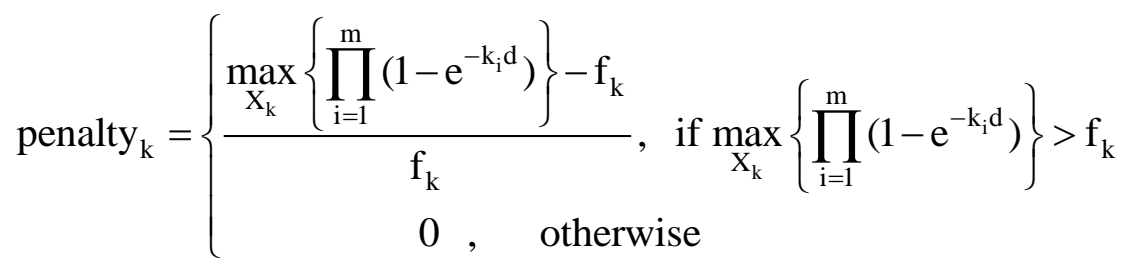

When the penalty function is defined as above, the original fitness function to any individual Eq. (3) of the IAPSO is penalized by containing the penalty function Eq. (8). 


\section{Numerical results and discussion}

To validate IAPSO performance, it was assumed that the type, number and location of the signal transmission stations are determined in various areas with different specified communication quality requirements to minimize the overall construction cost. To evaluate the performance of the proposed hybrid evolutionary approach for the multiple category signal transmission station location-allocation problems, a total of 24 test problems in three types of regions (refer to Fig. 4) with various communication quality and cost limitations were tested. We also assumed that three categories of signal transmission stations (i.e., Category A, B, and C) are with different setup cost (50, 30, and 20 respectively) and the corresponding signal decay exponents (1,3, and 5 respectively). These experimental problems were solved with different specified limitation of communication quality requirements in every sub-region. Three different regions for deploying the various signal transmission stations are illustrated in Figs. 4(a)-(c). Each type of regions includes different sub-regions with various specified communication quality requirements. These maps are used for our experimental studies.

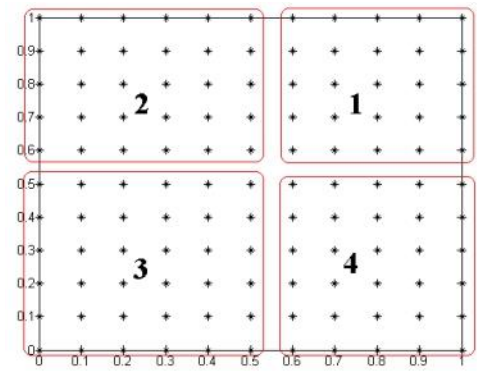

(a) Type 1 with four sub-regions

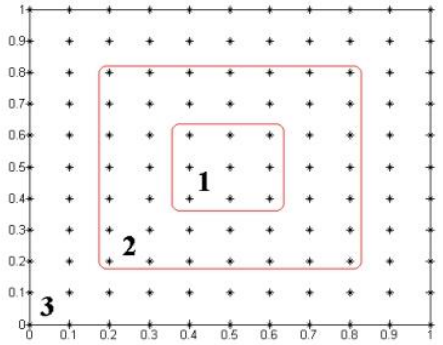

(b) Type 2with three sub-regions

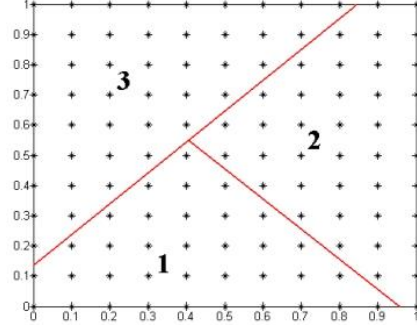

(c) Type 3 with three sub-regions

Fig. 4 Three types of deployment regions

The determination of IAPSO's parameters is a significant issue for the proposed algorithm implementation. Yet, there is no formal methodology to find the optimal parameters because various value-combinations of the parameters result to various characteristics as well as various performance of IAPSO. Therefore, it is noted that the most suitable values for the IAPSO parameters are case-dependent and based upon the experience from preliminary trials. The parameters of the proposed IAPSO are illustrated in Table 1. These input data of all the test problems and those of numerical results obtained by using the proposed IAPSO are all shown in the following three sections.

Table 1 Parameters of the proposed IAPSO

\begin{tabular}{|c|c|c|c|}
\hline Population size & 120 & Maximum clone number & 10 \\
\hline IA maximum generations & 50 & $\mathrm{C}_{1}$ & 2 \\
\hline PSO maximum generations & 500 & $\mathrm{C}_{2}$ & 2 \\
\hline Crossover rate & 0.89 & $\mathrm{~V}_{\max }$ & 0.025 \\
\hline Mutation rate & 0.02 & $\omega$ & 0.95 \\
\hline
\end{tabular}

\subsection{Region type 1}

The first type of deployment region is divided as four sub-regions, as shown in Fig. 4(a). There are 8 test problems with the distinct communication quality. In each sub-region of every test problem, the maximum failure rates of communication quality are randomly generated, and they are gradually decreasing in the following test problems, i.e., harder restriction. While the failure rate of each sub-regions is getting tighter, more signal communication stations are needed, and the cost will surely become higher as shown in Table 2, from test problems 1 to 8 . Recall that for each problem, the number of signal transmission stations and the corresponding category and location for each station are decided simultaneously.

The numerical results are shown in Table 2, where the detailed solutions obtained by the proposed IAPSO for the 8 test problems is described. Additionally, they are compared with those found by using LINGO ${ }^{\circledR}$. Each of the problems is with different maximum failure rates for the corresponding regions. The maximum failure rate of each area in all test problems is 
Table 2 Numerical results by the proposed IAPSO for Region type 1

\begin{tabular}{|c|c|c|c|c|c|c|c|c|}
\hline \multirow{2}{*}{ No. } & \multicolumn{4}{|c|}{$\begin{array}{l}\text { Maximum Failure rate for each sub-region } \\
\text { (specific communication quality requirement) }\end{array}$} & \multirow{2}{*}{$\begin{array}{l}\text { Minimum } \\
\text { Cost }\end{array}$} & \multicolumn{2}{|c|}{$\begin{array}{c}\text { Signal Communication } \\
\text { Stations } \\
\end{array}$} & \multirow{2}{*}{ Coordination } \\
\hline & \begin{tabular}{|c|} 
Sub-region \\
1
\end{tabular} & \begin{tabular}{|c|} 
Sub-region \\
2
\end{tabular} & \begin{tabular}{|c|} 
Sub-region \\
3
\end{tabular} & \begin{tabular}{|c|} 
Sub-region \\
4
\end{tabular} & & Category & Number & \\
\hline \multirow{3}{*}{1} & \multirow{3}{*}{0.156528} & \multirow{3}{*}{0.109168} & \multirow{3}{*}{0.052761} & \multirow{3}{*}{0.124815} & \multirow{3}{*}{200} & A & 3 & $\begin{array}{l}(0.1171,0.8372)(0.4149, \\
0.2789)(0.9146,0.8208)\end{array}$ \\
\hline & & & & & & $\mathrm{B}$ & 1 & $(0.9102,0.0934)$ \\
\hline & & & & & & $\mathrm{C}$ & 1 & $(0.0447,0.0938)$ \\
\hline \multirow[t]{2}{*}{2} & \multirow[t]{2}{*}{0.093513} & \multirow[t]{2}{*}{0.057209} & \multirow[t]{2}{*}{0.140462} & \multirow[t]{2}{*}{0.080683} & \multirow[t]{2}{*}{210} & A & 3 & $\begin{array}{c}(0.4670,0.5358) \\
(0.9001,0.8384)(0.1523 \\
0.1119) \\
\end{array}$ \\
\hline & & & & & & B & 2 & $\begin{array}{c}(0.0944,0.9107)(0.9051 \\
0.0859)\end{array}$ \\
\hline \multirow{3}{*}{3} & \multirow{3}{*}{0.057165} & \multirow{3}{*}{0.122406} & \multirow{3}{*}{0.040289} & \multirow{3}{*}{0.054679} & \multirow{3}{*}{260} & A & 3 & $\begin{array}{l}(0.8824,0.8843)(0.0389, \\
0.8496)(0.4099,0.2859)\end{array}$ \\
\hline & & & & & & B & 3 & $\begin{array}{l}(0.0442,0.1032)(0.7230 \\
0.3850)(0.9124,0.0563) \\
\end{array}$ \\
\hline & & & & & & $\mathrm{C}$ & 1 & $(0.6200,0.9251)$ \\
\hline \multirow{3}{*}{4} & \multirow{3}{*}{0.093537} & \multirow{3}{*}{0.083541} & \multirow{3}{*}{0.063834} & \multirow{3}{*}{0.030048} & \multirow{3}{*}{300} & A & 3 & $\begin{array}{l}(0.0846,0.0890)(0.0589, \\
0.8824)(0.9511,0.1044) \\
\end{array}$ \\
\hline & & & & & & B & 3 & $\begin{array}{l}(0.9855,0.9253)(0.5662 \\
0.1558)(0.3587,0.8692)\end{array}$ \\
\hline & & & & & & $\mathrm{C}$ & 3 & $\begin{array}{l}(0.7205,0.9060)(0.9850 \\
0.5487)(0.1827,0.5186) \\
\end{array}$ \\
\hline \multirow[t]{3}{*}{5} & \multirow[t]{3}{*}{0.007375} & \multirow[t]{3}{*}{0.010728} & \multirow[t]{3}{*}{0.030766} & 0.007233 & 350 & A & 6 & $\begin{array}{c}(0.4400,0.2700)(0.1662, \\
0.8499)(0.0635,0.0822) \\
(0.2507,0.5671)(0.7785, \\
0.7009)(0.9242,0.0523) \\
\end{array}$ \\
\hline & & & & & & B & 1 & $(0.9330,0.9692)$ \\
\hline & & & & & & $\mathrm{C}$ & 1 & $(0.8039,0.3590)$ \\
\hline 6 & 0.005343 & 0.004374 & 0.001580 & 0.006801 & 410 & A & 7 & $\begin{array}{c}(0.1373,0.1473)(0.9450, \\
0.9433)(0.6555,0.6192) \\
(0.9416,0.0475)(0.0365, \\
0.9274)(0.4514,0.3173) \\
(0.4127,0.7387)\end{array}$ \\
\hline & & & & & & B & 2 & $\begin{array}{c}(0.2378,0.5857)(0.7745 \\
0.4101)\end{array}$ \\
\hline & & & & & & A & 6 & $\begin{array}{c}(0.0415,0.0487)(0.7938, \\
0.7924)(0.7744,0.1797) \\
(0.2732,0.3166)(0.5654, \\
0.6677)(0.0624,0.9389) \\
\end{array}$ \\
\hline 7 & 0.002797 & 0.001488 & 0.019213 & 0.007564 & 470 & B & 5 & $\begin{array}{c}(0.5574,0.5470)(0.9680 \\
0.9603)(0.3352,0.5067) \\
(0.1733,0.8578)(0.9633 \\
0.0323) \\
\end{array}$ \\
\hline & & & & & & $\mathrm{C}$ & 2 & $\begin{array}{c}(0.9290,0.4132)(0.4201, \\
0.1597)\end{array}$ \\
\hline & & & & & & A & 6 & $\begin{array}{c}(0.5530,0.1877)(0.2688, \\
0.3599)(0.7281,0.6339) \\
(0.4585,0.6825)(0.9669, \\
0.9552)(0.3536,0.7523) \\
\end{array}$ \\
\hline 8 & 0.008464 & 0.001013 & 0.0019902 & 0.006127 & 540 & B & 6 & $\begin{array}{c}(0.1155,0.7873)(0.9725 \\
0.0395)(0.3894,0.3256) \\
(0.0333,0.0270)(0.8648, \\
0.4065)(0.0436,0.9798)\end{array}$ \\
\hline & & & & & & $\mathrm{C}$ & 3 & $\begin{array}{l}(0.8696,0.0959)(0.8160 \\
0.7831)(0.1481,0.1551) \\
\end{array}$ \\
\hline
\end{tabular}

generated in random numbers and is gradually reduced from test problems 1 to 8 . More budget means the scale of the problem will be larger. While each sub-region maximum failure rate is given for each problem, the types of signal stations and the corresponding numbers and locations are decided by using the proposed IAPSO approach simultaneously to minimize the total 
cost for setting up the stations in the specified region. When the types of signal transmission stations and the corresponding numbers and locations are decided in any test problem, the maximum failure rate in each sub-region should not be more than the specific value of the predefined failure rate in each sub-region. The numerical results in Tables 3 illustrate the detailed solutions obtained by the proposed approach for 8 test problems, and they are compared with the solutions obtained by using LINGO $^{\circledR}$.

Table 3 Comparison of the best solutions found by IAPSO with those of LINGO ${ }^{\circledR}$ for Region type 1

\begin{tabular}{|c|c|c|c|c|c|c|c|c|c|c|c|c|c|}
\hline & \multirow{2}{*}{\multicolumn{4}{|c|}{$\begin{array}{l}\text { Constraints: maximum failure rates of sub-regions } \\
\text { (specific communication quality requirement) }\end{array}$}} & \multicolumn{4}{|c|}{ LINGO $8.0^{\circledR}$} & \multicolumn{4}{|c|}{ IAPSO } & \multirow{3}{*}{$\begin{array}{c}\text { Solution } \\
\text { Compariso } \\
\mathrm{n}\end{array}$} \\
\hline & & & & & \multicolumn{3}{|c|}{$\begin{array}{c}\text { Signal } \\
\text { Stations } \\
\text { Category }\end{array}$} & \multirow{2}{*}{$\begin{array}{l}\text { Minimu } \\
\mathrm{m} \text { Cost }\end{array}$} & \multicolumn{3}{|c|}{$\begin{array}{c}\text { Signal } \\
\text { Stations } \\
\text { Category }\end{array}$} & \multirow{2}{*}{$\begin{array}{l}\text { Minimu } \\
\mathrm{m} \text { Cost }\end{array}$} & \\
\hline No & $\begin{array}{c}\text { Sub-regio } \\
\mathrm{n} 1\end{array}$ & $\begin{array}{c}\text { Sub-regio } \\
\text { n } 2\end{array}$ & $\begin{array}{c}\text { Sub-regio } \\
\text { n } 3\end{array}$ & $\begin{array}{c}\text { Sub-regio } \\
\text { n } 4\end{array}$ & A & B & $\mathrm{C}$ & & A & B & $\mathrm{C}$ & & \\
\hline 1 & 0.156528 & 0.109168 & 0.052761 & 0.124815 & 3 & 1 & 1 & 200 & 3 & 1 & 1 & 200 & 0 \\
\hline 2 & 0.093513 & 0.057209 & 0.140462 & 0.080683 & 3 & 2 & 0 & 210 & 3 & 2 & 0 & 210 & 0 \\
\hline 3 & 0.057165 & 0.122406 & 0.040289 & 0.054679 & 3 & 3 & 1 & 260 & 3 & 3 & 1 & 260 & 0 \\
\hline 4 & 0.093537 & 0.083541 & 0.063834 & 0.030048 & 3 & 3 & 3 & 300 & 3 & 3 & 3 & 300 & 0 \\
\hline 5 & 0.007375 & 0.010728 & 0.030766 & 0.007233 & 6 & 1 & 1 & 350 & 6 & 1 & 1 & 350 & 0 \\
\hline 6 & 0.005343 & 0.004374 & 0.00158 & 0.006801 & 7 & 1 & 2 & 420 & 7 & 2 & $\mathbf{0}$ & 410 & (2) \\
\hline 7 & 0.002797 & 0.001488 & 0.019213 & 0.007564 & 7 & 3 & 0 & 500 & 6 & 5 & 2 & 470 & (2) \\
\hline 8 & 0.008464 & 0.001013 & 0.0019902 & 0.006127 & 6 & 7 & 4 & 590 & 6 & 6 & 3 & 540 & (a) \\
\hline
\end{tabular}

Note: () represents the best solution of IAPSO is superior to the solution found by LINGO ${ }^{\circledR}$

$\circ$ represents the best solution of IAPSO is as well as the solution found by LINGO ${ }^{\circledR}$

The results in Table 3 indicate that:

(1) Compared with the solutions of all test problems obtained by LINGO®, all the eight test problems obtained by the proposed IAPSO approach are superior to or as well as those found by using LINGO ${ }^{\circledR}$. The solutions of five test problems found by both approaches are the same as those obtained by using both of the approaches;

(2) The solutions of the last three test problems obtained by the proposed IAPSO approach are superior to those obtained by

LINGO $^{\circledR}$. The improvement of the last three problems (problem 6-8) are 10, 30, and 50 units of total cost, respectively.

According to the above observations, it shows that while those solutions obtained by the proposed IAPSO method are superior to those found by $\mathrm{LINGO}^{\circledR}$, the maximum improvement can be up to 50 units of total cost. It can be summarized that the proposed approach is an effective approach for solving the signal transmission stations deployment problems investigated in the Region type 1.

\subsection{Region type 2}

Table 4 Numerical results by the proposed hybrid meta-evolutionary approach for Region type 2 (continued)

\begin{tabular}{|c|c|c|c|c|c|c|c|}
\hline \multirow[t]{2}{*}{ No. } & \multicolumn{3}{|c|}{$\begin{array}{l}\text { Maximum Failure rate for each } \\
\text { sub-region } \\
\text { (specific communication quality } \\
\text { requirement) }\end{array}$} & \multirow[t]{2}{*}{$\begin{array}{l}\text { Minimum } \\
\text { Cost }\end{array}$} & \multicolumn{2}{|c|}{$\begin{array}{l}\text { Signal Communication } \\
\text { Stations }\end{array}$} & \multirow[t]{2}{*}{ Coordination } \\
\hline & Sub-region 1 & Sub-region 2 & Sub-region 3 & & Category & Number & \\
\hline \multirow{3}{*}{1} & \multirow{3}{*}{0.007857} & \multirow{3}{*}{0.07200} & \multirow{3}{*}{0.144470} & \multirow{3}{*}{260} & A & 3 & $\begin{array}{c}(0.4801,0.6733)(0.8667,0.0953) \\
(0.6283,0.5758)\end{array}$ \\
\hline & & & & & B & 3 & $\begin{array}{c}(0.0453,0.9077)(0.0838,0.0596) \\
(0.2819,0.3970)\end{array}$ \\
\hline & & & & & $\mathrm{C}$ & 1 & $(0.9375,0.9420)$ \\
\hline \multirow{3}{*}{2} & \multirow{3}{*}{0.006437} & \multirow{3}{*}{0.065613} & \multirow{3}{*}{0.131947} & \multirow{3}{*}{280} & A & 3 & $\begin{array}{c}(0.2101,0.3866)(0.9107,0.8889) \\
(0.9186,0.1045)\end{array}$ \\
\hline & & & & & B & 3 & $\begin{array}{c}(0.6394,0.5963)(0.3356,0.7631) \\
(0.0497,0.9157)\end{array}$ \\
\hline & & & & & $\mathrm{C}$ & 2 & $(0.0498,0.5157)(0.4234,0.1026)$ \\
\hline
\end{tabular}


Table 4 Numerical results by the proposed hybrid meta-evolutionary approach for Region type 2

\begin{tabular}{|c|c|c|c|c|c|c|c|}
\hline \multirow[t]{2}{*}{ No. } & \multicolumn{3}{|c|}{$\begin{array}{l}\text { Maximum Failure rate for each } \\
\text { sub-region } \\
\text { (specific communication quality } \\
\text { requirement) }\end{array}$} & \multirow[t]{2}{*}{$\begin{array}{l}\text { Minimum } \\
\text { Cost }\end{array}$} & \multicolumn{2}{|c|}{$\begin{array}{c}\text { Signal Communication } \\
\text { Stations }\end{array}$} & \multirow[t]{2}{*}{ Coordination } \\
\hline & Sub-region 1 & Sub-region 2 & Sub-region 3 & & Category & Number & \\
\hline \multirow[t]{3}{*}{3} & \multirow[t]{3}{*}{0.001051} & \multirow[t]{3}{*}{0.005337} & \multirow[t]{3}{*}{0.030952} & \multirow[t]{3}{*}{350} & A & 6 & $\begin{array}{c}(0.9400,0.0819)(0.0635,0.9008) \\
(0.0720,0.0804) \\
(0.6292,0.6341)(0.9242,0.9287) \\
(0.5446,0.3713)\end{array}$ \\
\hline & & & & & $\mathrm{B}$ & 1 & $(0.2646,0.3087)$ \\
\hline & & & & & $\mathrm{C}$ & 1 & $(0.2187,0.8962)$ \\
\hline \multirow[t]{2}{*}{4} & \multirow[t]{2}{*}{0.000702} & \multirow[t]{2}{*}{0.016345} & \multirow[t]{2}{*}{0.017193} & \multirow[t]{2}{*}{410} & A & 7 & $\begin{array}{c}(0.0454,0.0626)(0.1985,0.6681) \\
(0.5365,0.8031) \\
(0.3799,0.3220)(0.6296,0.3477) \\
(0.9511,0.0597) \\
(0.7478,0.6544)\end{array}$ \\
\hline & & & & & $\mathrm{B}$ & 2 & $(0.9617,0.9582)(0.0503,0.9736)$ \\
\hline \multirow[t]{3}{*}{5} & \multirow[t]{3}{*}{0.001972} & \multirow[t]{3}{*}{0.009483} & \multirow[t]{3}{*}{0.008417} & \multirow[t]{3}{*}{430} & A & 6 & $\begin{array}{c}(0.9104,0.9279)(0.9556,0.0699) \\
(0.3204,0.5676) \\
(0.2911,0.2188)(0.7178,0.6671) \\
(0.0585,0.9119)\end{array}$ \\
\hline & & & & & B & 3 & $\begin{array}{c}(0.7548,0.2115)(0.8030,0.8115) \\
(0.1878,0.9458)\end{array}$ \\
\hline & & & & & $\mathrm{C}$ & 2 & $(0.0208,0.0427)(0.1132,0.4560)$ \\
\hline \multirow{3}{*}{6} & \multirow{3}{*}{0.000106} & \multirow{3}{*}{0.015656} & \multirow{3}{*}{0.027329} & \multirow{3}{*}{460} & A & 5 & $\begin{array}{c}(0.4558,0.2816)(0.0871,0.3363) \\
(0.9689,0.0533) \\
(0.2289,0.8014)(0.9602,0.9523)\end{array}$ \\
\hline & & & & & $\mathrm{B}$ & 5 & $\begin{array}{c}(0.6334,0.9071)(0.6687,0.1280) \\
(0.0497,0.9654) \\
(0.2496,0.7092)(0.8839,0.6412)\end{array}$ \\
\hline & & & & & $\mathrm{C}$ & 3 & $\begin{array}{c}(0.0264,0.0291)(0.2582,0.0651) \\
(0.8570,0.3484)\end{array}$ \\
\hline \multirow{3}{*}{7} & \multirow{3}{*}{0.000511} & \multirow{3}{*}{0.013258} & \multirow{3}{*}{0.009265} & \multirow{3}{*}{510} & A & 6 & $\begin{array}{c}(0.8349,0.7796)(0.2826,0.3126) \\
(0.6276,0.2445) \\
(0.8402,0.3734)(0.2292,0.7971) \\
(0.3757,0.5840) \\
\end{array}$ \\
\hline & & & & & B & 5 & $\begin{array}{c}(0.1832,0.1997)(0.0424,0.0195) \\
(0.6681,0.9023) \\
(0.0309,0.9667)(0.7498,0.1636)\end{array}$ \\
\hline & & & & & $\mathrm{C}$ & 3 & $\begin{array}{c}(0.9794,0.9688)(0.9760,0.0294) \\
(0.0344,0.6741)\end{array}$ \\
\hline \multirow{3}{*}{8} & \multirow{3}{*}{0.000856} & \multirow{3}{*}{0.010455} & \multirow{3}{*}{0.006125} & \multirow{3}{*}{540} & A & 6 & $\begin{array}{c}(0.4328,0.4319)(0.8033,0.5720) \\
(0.5492,0.3070) \\
(0.7309,0.8470)(0.0478,0.0304) \\
(0.7651,0.2172)\end{array}$ \\
\hline & & & & & B & 6 & $\begin{array}{c}(0.1910,0.8756)(0.2406,0.4403) \\
(0.1742,0.4844) \\
(0.3257,0.7093)(0.0200,0.9604) \\
(0.5284,0.6606) \\
\end{array}$ \\
\hline & & & & & $\mathrm{C}$ & 3 & $\begin{array}{c}(0.6545,0.6064)(0.9745,0.0306) \\
(0.9759,0.9708)\end{array}$ \\
\hline
\end{tabular}

The second type of deployment region is divided into three square sub-regions with an identical center as shown in Fig. 4(b). Eight test problems with different restrictions of each sub-regions' communication quality are used to evaluate the performance of the proposed IAPSO approach. If the limitation (failure rate) of communication quality in each sub-regions is getting tighter, more stations are needed, and surely the cost will be more abundant, as shown in Table 4, from test problems 1 to 8 .

Tables 5 illustrates the comparison of the best solution found by IAPSO with those of LINGO ${ }^{\circledR}$ for Region type 2 , and it indicates that: 
(1) None of the solutions found by the proposed IAPSO approach are inferior to those found by using LINGO $^{\circledR}$;

(2) The solutions of four test problems obtained by the proposed IAPSO approach are superior to those obtained by LINGO ${ }^{\circledR}$.

Moreover, it shows that an improvement of problems 4, 5, 7, and 8 are 20, 20, 20, and 30 units of the total cost, respectively. Based on the above experimental results, it concludes that the performance of the proposed approach is superior to or as well as that of $\mathrm{LINGO}^{\circledR}$ for solving the signal transmission station deployment problems investigated in the Region type 2 .

Table 5 Comparison of the best solutions found by IAPSO with those of LINGO ${ }^{\circledR}$ for Region type 2

\begin{tabular}{|c|c|c|c|c|c|c|c|c|c|c|c|c|}
\hline & \multirow{2}{*}{\multicolumn{3}{|c|}{$\begin{array}{l}\text { Constraints: maximum failure rates of } \\
\text { sub-regions } \\
\text { (specific communication quality } \\
\text { requirement) }\end{array}$}} & \multicolumn{4}{|c|}{ LINGO $8.0^{\mathbb{R}}$} & \multicolumn{4}{|c|}{ IAPSO } & \multirow{3}{*}{$\begin{array}{c}\text { Solution } \\
\text { Comparison }\end{array}$} \\
\hline & & & & \multicolumn{3}{|c|}{$\begin{array}{c}\text { Signal } \\
\text { Stations } \\
\text { Category }\end{array}$} & \multirow{2}{*}{$\begin{array}{l}\text { Minimum } \\
\text { Cost }\end{array}$} & \multicolumn{3}{|c|}{$\begin{array}{c}\text { Signal } \\
\text { Stations } \\
\text { Category }\end{array}$} & \multirow{2}{*}{$\begin{array}{l}\text { Minimum } \\
\text { Cost }\end{array}$} & \\
\hline No. & $\begin{array}{c}\text { Sub-region } \\
1\end{array}$ & $\begin{array}{c}\text { Sub-region } \\
2\end{array}$ & $\begin{array}{c}\text { Sub-region } \\
3\end{array}$ & A & B & $\mathrm{C}$ & & $\mathrm{A}$ & B & $\mathrm{C}$ & & \\
\hline 1 & 0.007857 & 0.072000 & 0.144470 & 3 & 3 & 1 & 260 & 3 & 3 & 1 & 260 & 0 \\
\hline 2 & 0.006437 & 0.065613 & 0.131947 & 3 & 3 & 2 & 280 & 3 & 3 & 2 & 280 & 0 \\
\hline 3 & 0.001051 & 0.005337 & 0.030952 & 6 & 1 & 1 & 350 & 6 & 1 & 1 & 350 & 0 \\
\hline 4 & 0.000702 & 0.016345 & 0.017193 & 7 & 2 & 1 & 430 & 7 & 2 & 0 & 410 & (2) \\
\hline 5 & 0.001972 & 0.009483 & 0.008417 & 6 & 3 & 3 & 450 & 6 & 3 & 2 & 430 & (2) \\
\hline 6 & 0.000106 & 0.015656 & 0.027329 & 5 & 5 & 3 & 460 & 5 & 5 & 3 & 460 & 0 \\
\hline 7 & 0.000511 & 0.013258 & 0.009265 & 6 & 5 & 4 & 530 & 6 & 5 & 3 & 510 & (2) \\
\hline 8 & 0.000856 & 0.010455 & 0.006125 & 6 & 4 & 3 & 570 & 6 & 6 & 3 & 540 & (2) \\
\hline
\end{tabular}

Note: () represents the best solution of IAPSO is superior to the solution found by LINGO ${ }^{\circledR}$

$\circ$ represents the best solution of IAPSO is as well as the solution found by LINGO ${ }^{\circledR}$

\subsection{Region type 3}

Table 6 Numerical results by the proposed hybrid meta-evolutionary approach for Region type 3 (continued)

\begin{tabular}{|c|c|c|c|c|c|c|c|}
\hline \multirow[t]{2}{*}{ No. } & \multicolumn{3}{|c|}{$\begin{array}{l}\text { Maximum Failure rate for each } \\
\text { sub-region } \\
\text { (specific communication quality } \\
\text { requirement) }\end{array}$} & \multirow[t]{2}{*}{$\begin{array}{l}\text { Minimum } \\
\text { Cost }\end{array}$} & \multicolumn{2}{|c|}{$\begin{array}{c}\text { Signal Communication } \\
\text { Stations }\end{array}$} & \multirow[t]{2}{*}{ Coordination } \\
\hline & Sub-region 1 & Sub-region 2 & Sub-region 3 & & Category & Number & \\
\hline \multirow{3}{*}{1} & \multirow{3}{*}{0.116085} & \multirow{3}{*}{0.101736} & \multirow{3}{*}{0.074877} & \multirow{3}{*}{280} & A & 3 & $\begin{array}{c}(0.2514,0.7960)(0.3528,0.4257) \\
(0.8533,0.4417)\end{array}$ \\
\hline & & & & & B & 3 & $\begin{array}{c}(0.6504,0.1002)(0.9595,0.9044) \\
(0.6928,0.8043)\end{array}$ \\
\hline & & & & & $\mathrm{C}$ & 2 & $(0.0264,0.9277)(0.0452,0.0682)$ \\
\hline \multirow{3}{*}{2} & \multirow{3}{*}{0.064810} & \multirow{3}{*}{0.084687} & \multirow{3}{*}{0.018261} & \multirow{3}{*}{290} & A & 3 & $\begin{array}{c}(0.3556,0.1562)(0.4935,0.6714) \\
(0.4001,0.5457) \\
(0.9346,0.8589)\end{array}$ \\
\hline & & & & & $\mathrm{B}$ & 1 & $(0.9552,0.0840)$ \\
\hline & & & & & $\mathrm{C}$ & 3 & $\begin{array}{c}(0.0456,0.1907)(0.6942,0.2248) \\
(0.0485,0.9389)\end{array}$ \\
\hline \multirow{3}{*}{3} & \multirow{3}{*}{0.020200} & \multirow{3}{*}{0.033798} & \multirow{3}{*}{0.01104} & \multirow{3}{*}{380} & A & 5 & $\begin{array}{c}(0.4482,0.8722)(0.2049,0.2330) \\
(0.9151,0.9590) \\
(0.7662,0.4279)(0.4882,0.5366)\end{array}$ \\
\hline & & & & & $\mathrm{B}$ & 3 & $\begin{array}{c}(0.9507,0.0422)(0.1620,0.8182) \\
(0.0760,0.9466)\end{array}$ \\
\hline & & & & & $\mathrm{C}$ & 2 & $(0.0499,0.0245)(0.5800,0.1523)$ \\
\hline \multirow[t]{2}{*}{4} & \multirow[t]{2}{*}{0.11965} & \multirow[t]{2}{*}{0.005197} & \multirow[t]{2}{*}{0.005117} & \multirow[t]{2}{*}{410} & A & 7 & $\begin{array}{c}(0.0617,0.0419)(0.3899,0.2812) \\
(0.0453,0.9443) \\
(0.4382,0.8174)(0.9404,0.0522) \\
(0.9290,0.9652) \\
(0.7113,0.3063)\end{array}$ \\
\hline & & & & & $\mathrm{B}$ & 2 & $(0.8670,0.6803)(0.1270,0.5007)$ \\
\hline
\end{tabular}


Table 6 Numerical results by the proposed hybrid meta-evolutionary approach for Region type 3

\begin{tabular}{|c|c|c|c|c|c|c|c|}
\hline \multirow[t]{2}{*}{ No. } & \multicolumn{3}{|c|}{$\begin{array}{l}\text { Maximum Failure rate for each } \\
\text { sub-region } \\
\text { (specific communication quality } \\
\text { requirement) }\end{array}$} & \multirow[t]{2}{*}{$\begin{array}{l}\text { Minimum } \\
\text { Cost }\end{array}$} & \multicolumn{2}{|c|}{$\begin{array}{c}\text { Signal Communication } \\
\text { Stations }\end{array}$} & \multirow[t]{2}{*}{ Coordination } \\
\hline & Sub-region 1 & Sub-region 2 & Sub-region 3 & & Category & Number & \\
\hline \multirow{3}{*}{5} & \multirow{3}{*}{0.006496} & \multirow{3}{*}{0.009283} & \multirow{3}{*}{0.003139} & \multirow{3}{*}{460} & A & 6 & $\begin{array}{c}(0.0457,0.0529)(0.6480,0.8536) \\
(0.1738,0.2471) \\
(0.8586,0.6879)(0.0457,0.9542) \\
(0.7895,0.1085)\end{array}$ \\
\hline & & & & & B & 4 & $\begin{array}{c}(0.9602,0.9687)(0.2813,0.8500) \\
(0.1479,0.5927) \\
(0.9157,0.3394)\end{array}$ \\
\hline & & & & & $\mathrm{C}$ & 2 & $(0.9841,0.0390)(0.4583,0.0106)$ \\
\hline \multirow{3}{*}{6} & \multirow{3}{*}{0.006711} & \multirow{3}{*}{0.013316} & \multirow{3}{*}{0.003959} & \multirow{3}{*}{490} & A & 6 & $\begin{array}{c}(0.4849,0.6440)(0.2072,0.2334) \\
(0.0402,0.9499) \\
(0.2815,0.6686)(0.4470,0.4367) \\
(0.9493,0.0229)\end{array}$ \\
\hline & & & & & B & 5 & $\begin{array}{c}(0.9291,0.3370)(0.8770,0.7860) \\
(0.5791,0.0955) \\
(0.0435,0.0298)(0.8301,0.5801)\end{array}$ \\
\hline & & & & & $\mathrm{C}$ & 2 & $(0.5098,0.9205)(0.9604,0.9918)$ \\
\hline \multirow{3}{*}{7} & \multirow{3}{*}{0.004416} & \multirow{3}{*}{0.008213} & \multirow{3}{*}{0.002969} & \multirow{3}{*}{510} & A & 6 & $\begin{array}{c}(0.7862,0.7830)(0.8315,0.2296) \\
(0.4914,0.4478) \\
(0.0403,0.9511)(0.2450,0.6267) \\
(0.1633,0.2181) \\
\end{array}$ \\
\hline & & & & & B & 5 & $\begin{array}{c}(0.3638,0.6875)(0.9785,0.9578) \\
(0.4885,0.0852) \\
(0.9625,0.0256)(0.5663,0.8069)\end{array}$ \\
\hline & & & & & $\mathrm{C}$ & 3 & $\begin{array}{c}(0.8596,0.5155)(0.0261,0.0293) \\
(0.3594,0.9406)\end{array}$ \\
\hline \multirow[t]{3}{*}{8} & \multirow[t]{3}{*}{0.000577} & \multirow[t]{3}{*}{0.003565} & \multirow[t]{3}{*}{0.001441} & \multirow[t]{3}{*}{560} & $\mathrm{~A}: 9$ & 9 & $\begin{array}{c}(0.5638,0.5500)(0.8468,0.2969) \\
(0.0260,0.9563) \\
(0.7506,0.7488)(0.0476,0.0183) \\
(0.4793,0.1013) \\
(0.1580,0.2553)(0.9586,0.9716) \\
(0.1651,0.7011) \\
\end{array}$ \\
\hline & & & & & B:3 & 3 & $\begin{array}{c}(0.3803,0.8731)(0.9598,0.0192) \\
(0.3680,0.5647)\end{array}$ \\
\hline & & & & & $\mathrm{C}: 1$ & 1 & $(0.8565,0.0852)$ \\
\hline
\end{tabular}

The third type of deployment region as shown in Fig. 4(c) is divided into three triangle-like sub-regions. The numerical results obtained by using the proposed IAPSO approach based on the Type 3 region with varying the restriction of each sub-region's communication quality. If the restriction (failure rate) of communication quality in each sub-region is getting tighter, more cost will be required, as shown in Table 6 from test problems 1 to 8 . The coordination of each stations are also presented in the Table.

Table 7 presents the numerical results comparison between the best solutions found by our approach and those found by LINGO $^{\circledR}$. It indicates that:

(1) None solutions of the eight test problems obtained by the proposed IAPSO approach are worse than those found by using LINGO $^{\circledR}$;

(2) Solutions of the first three test problems solved by both methods are the same.

However, the performance of our proposed approach is better than that of LINGO ${ }^{\circledR}$ in the last five problems (problem 4-8). It concludes that the proposed method is a practical approach for solving the station deployment problem investigated in the Region type 3. 
Table 7 Comparison of the best solutions found by IAPSO with those of LINGO ${ }^{\circledR}$ for Region type 3

\begin{tabular}{|c|c|c|c|c|c|c|c|c|c|c|c|c|}
\hline & \multirow{2}{*}{\multicolumn{3}{|c|}{$\begin{array}{l}\text { Constraints: maximum failure rates of } \\
\text { sub-regions } \\
\text { (specific communication quality } \\
\text { requirement) }\end{array}$}} & \multicolumn{4}{|c|}{ LINGO $8.0^{(\mathbb{R}}$} & \multicolumn{4}{|c|}{ IAPSO } & \multirow{3}{*}{$\begin{array}{c}\text { Solution } \\
\text { Comparison }\end{array}$} \\
\hline & & & & \multicolumn{3}{|c|}{$\begin{array}{l}\text { Signal } \\
\text { Stations } \\
\text { Category }\end{array}$} & \multirow{2}{*}{$\begin{array}{l}\text { Minimum } \\
\text { Cost }\end{array}$} & \multicolumn{3}{|c|}{$\begin{array}{l}\text { Signal } \\
\text { Stations } \\
\text { Category }\end{array}$} & \multirow{2}{*}{$\begin{array}{l}\text { Minimum } \\
\text { Cost }\end{array}$} & \\
\hline No. & $\begin{array}{c}\text { Sub-region } \\
1\end{array}$ & $\begin{array}{c}\text { Sub-region } \\
2\end{array}$ & $\begin{array}{c}\text { Sub-region } \\
3\end{array}$ & A & B & $\mathrm{C}$ & & A & B & $\mathrm{C}$ & & \\
\hline 1 & 0.116085 & 0.101736 & 0.074877 & 3 & 3 & 2 & 280 & 3 & 3 & 2 & 280 & 0 \\
\hline 2 & 0.06481 & 0.084687 & 0.018261 & 4 & 1 & 3 & 290 & 4 & 1 & 3 & 290 & 0 \\
\hline 3 & 0.0202 & 0.033798 & 0.011040 & 5 & 3 & 2 & 380 & 5 & 3 & 2 & 380 & 0 \\
\hline 4 & 0.11965 & 0.005197 & 0.005117 & 7 & 1 & 2 & 420 & 7 & 2 & 0 & 410 & (2) \\
\hline 5 & 0.006496 & 0.009283 & 0.003139 & 6 & 4 & 3 & 480 & 6 & 4 & 2 & 460 & (2) \\
\hline 6 & 0.006711 & 0.013316 & 0.003959 & 6 & 6 & 1 & 500 & 6 & 5 & 2 & 490 & (2) \\
\hline 7 & 0.004416 & 0.008213 & 0.002969 & 6 & 6 & 3 & 540 & 6 & 5 & 3 & 510 & (2) \\
\hline 8 & 0.000577 & 0.003565 & 0.001441 & 9 & 4 & 1 & 590 & 9 & 3 & 1 & 560 & (2) \\
\hline
\end{tabular}

Note: () represents the best solution of IAPSO is superior to the solution found by LINGO ${ }^{\circledR}$

$\circ$ represents the best solution of IAPSO is as well as the solution found by LINGO ${ }^{\circledR}$

According to the experimental results (Section 4.1-4.3) for solving the above three different regional problems in Tables 3, 5 and 7, the results show that when the restrictive conditions are more stringent, the performance of the proposed IAPSO will be more excellent than Lingo.

\section{Conclusions}

This paper presents a hybrid evolutionary algorithm named IAPSO, for solving nonlinearly constrained signal transmission station location and allocation problems in which each region is with different communication quality restrictions. In this problem, while it is constrained with regional various communication quality restrictions, the types of signal detectors and the corresponding numbers and locations are decided simultaneously to minimize the total set up cost of the signal transmission stations. It is noted that the proposed method combines the advantages of IA and PSO to solve this problem. First, it's taking the merit of IA's global solution searching ability to decide the number of the signal transmission stations and the category of each station at the same time. Then, it's taking the merit of PSO's quick convergence speed to determine the best locations for all stations.

According to the experimental results, it shows that the proposed IAPSO finds the solutions which are of a quality and comparable to that of LINGO ${ }^{\circledR}$. The proposed method achieves the optimal solution or finds a near-optimal solution for each tested problem. In general, the numerical results show that the proposed approach is valid for this signal transmission station location and allocation problems.

\section{Acknowledgments}

The research is supported by National Science Council, Taiwan, under contract 108-2221-E-468-009.

\section{Conflicts of Interest}

The authors declare no conflict of interest.

\section{References}

[1] E. C. Chukwuma, "Facility location-allocation modelling for bio-energy system in Anambra state of Nigeria: Integration of GIS and location model," Renewable Energy, vol. 141, pp. 460-467, October 2019.

[2] C. T. Cicek, H. Gultekin, and B. Tavli, "The location-allocation problem of drone base stations computers \& operations research,” Computers \& Operations Research, vol. 111, pp. 155-176, November 2019 
[3] M. Alizadeh, J. Ma, N. Mahdavi-Amiri, M. Marufuzzaman, and R. Jaradat, "A stochastic programming model for a capacitated location-allocation problem with heterogeneous demands," Computers \& Industrial Engineering, vol. 137, article 106055, November 2019.

[4] “5G,” https://en.wikipedia.org/wiki/5G, Wikipedia, 2018.

[5] Z. Drezner and G. O. Wesolowsky, “On the best location of signal detectors," IIE Transactions, vol. 29, no. 11, pp. 1007-1015, March 1997.

[6] F. Plastria, Continuous location problems, in Facility Location: A Survey of Applications and Methods, Drezner, Z., ed., Springer-Verlag, New York, pp. 229-266, January 1995.

[7] R.F. Love, J.G. Morris, and G.O. Wesolowsky, Facilities Location: Models and Methods, North-Holland, New York, 1988.

[8] T. C. Chen, S. C. Wang, C. H. Wu, and K. W. Huang, "Using two-phase evolutionary computation approach for nonlinear constrained signal detectors allocation problems," Journal of Intelligent and Fuzzy Systems, vol. 36, no. 2, pp. 1301-1310, March 2019.

[9] N.K. Jerne, Clonal selection in lymphocyte network, in: G.M. Edelman, ed., Cellular Selection and Regulation in the Immune Response, Raven Press, New York, 1974.

[10] B. Geng, L. Jiao, M. Gong, L. Li, and Y. Wu, “A two-step personalized location recommendation based on multi-objective immune algorithm,” Information Sciences, vol. 475, pp. 161-181, February 2019.

[11] T. C. Chen, "IAs based approach for reliability redundancy allocation problems," Applied Mathematics and Computation, vol. 182, no. 2, pp. 1556-1567, November 2006.

[12] Y. Jiang, K. Hao, X. Cai, and Y. Ding, "An improved reinforcement immune algorithm for agricultural resource allocation optimization," Journal of Computational Science, vol. 27, pp. 320-328, July 2018.

[13] J. Kennedy and R. Eberhart, Particle swarm optimization, Proc. of ICNN'95 - International Conference on Neural Networks, IEEE Press, August 1995, pp. 1942-1948.

[14] Y. Shi and R Eberhart, A modified particle swarm optimizer, 1998 IEEE international conference on evolutionary computation proceedings. IEEE world congress on computational intelligence (Cat. No. 98TH8360), May 1998, pp. 69-73.

[15] A. Sallama, M. Abbod, and S. M. Khan, “Applying sequential particle Swarm optimization algorithm to improve power generation quality," International Journal of Engineering and Technology Innovation, vol. 4, no. 4, pp. 223-233, October 2014.

[16] C. L. Lu and T. C. Lin, "Improved SVM classifier incorporating adaptive condensed instances based on hybrid continuous-discrete particle swarm optimization," Advances in Technology Innovation, vol. 1, no. 2, pp. 53-57, September 2016.

[17] Y. C. Hsieh, Y. C. Lee, P. S. You, and T. C. Chen, "An immune based two-phase approach for the multiple-type surveillance camera location problem," Expert Systems with Applications, vol. 36, no. 7, pp. 10634 -10639, September 2009.

[18] Y. Shi and R. C. Eberhart, “A modified particle swarm optimizer,” IEEE International Conference on Evolutionary Computation Proceedings. IEEE World Congress on Computational Intelligence (Cat. No.98TH8360), May 1998, pp. 69-73.

[19] Z. Michalewicz, Genetic algorithms+ data structures= evolution programs, 3rd ed. Springer-Verlag Berlin Heidelberg: NY, 1996.

Copyright $(\mathrm{C}$ by the authors. Licensee TAETI, Taiwan. This article is an open access article distributed under the terms and conditions of the Creative Commons Attribution (CC BY-NC) license (https://creativecommons.org/licenses/by-nc/4.0/). 